\title{
Expression levels of induced sputum IL-8 and IL-10 and drug intervention effects in patients with acute exacerbated COPD complicated with chronic cor pulmonale at high altitude
}

\author{
ENZHI FENG ${ }^{1 *}$, RONGHUA WAN ${ }^{2 *}$, SHENGYUE YANG ${ }^{1}$, ZIQIANG YAN $^{1}$, SHAOLIN WANG $^{1}$, \\ WEI HE ${ }^{1}$, YING ZHANG ${ }^{1}$, HE YIN ${ }^{1}$, ZONGRU CHEN ${ }^{1}$ and RUINIAN LIU ${ }^{1}$ \\ ${ }^{1}$ Center of Respiratory Medicine, The Fourth Hospital of PLA, Lanzhou Command, Xining, Qinghai 810007; \\ ${ }^{2}$ Department of Cardiovascular Surgery, Heart Center, General Hospital of Ningxia Medical University, \\ Yinchuan, Ningxia 750004, P.R. China
}

Received March 26, 2013; Accepted June 19, 2013

DOI: $10.3892 /$ etm.2013.1192

\begin{abstract}
The aim of this study was to assess the expression levels of induced sputum interleukin (IL)-8 and IL-10 levels in patients with acute exacerbated chronic obstructive pulmonary disease (AECOPD) complicated with chronic cor pulmonale (CCP) at high altitude, and to evaluate the intervention effects of an inhaled corticosteroid (ICS) and a $\beta_{2}$-adrenoceptor agonist in this disease. A total of 186 patients with AECOPD complicated with $\mathrm{CCP}$ were randomly divided into three groups, with 62 cases in each. With regard to the two treatment groups, group A was treated with salmeterol/fluticasone (50 $\mu \mathrm{g} / 250 \mu \mathrm{g}$, respectively) by airway inhalation twice daily, while group B received budesonide $(1 \mathrm{mg})$ as a spray inhalation, twice daily. The routine treatment group (group C) received only routine treatment. The levels of IL- 8 and IL-10 in the induced sputum and the predicted percentage of forced expiratory volume in one second $\left(\mathrm{FEV}_{1 \% \mathrm{pred}}\right)$, partial pressure of oxygen in arterial blood $\left(\mathrm{PaO}_{2}\right)$ and partial pressure of carbon dioxide in arterial blood $\left(\mathrm{PaCO}_{2}\right)$ were examined on admission and at a stable stage two weeks following treatment. Forty healthy volunteers served as a control group (group D). Compared with group D values, the IL-8 induced sputum level and the $\mathrm{PaCO}_{2}$ were significantly increased, while the level of IL-10, $\mathrm{FEV}_{1 \% \text { pred }}$ and the $\mathrm{PaO}_{2}$ were markedly decreased in the three COPD groups prior to treatment. Following treatment, the induced sputum IL-8 level and the $\mathrm{PaCO}_{2}$ were significantly decreased, while
\end{abstract}

Correspondence to: Dr Shengyue Yang, Center of Respiratory Medicine, The Fourth Hospital of PLA, Lanzhou Command, No. 67 Bayi Dong Road, Xining, Qinghai 810007, P.R. China

E-mail: shengyueyangcn@163.com

*Contributed equally

Key words: interleukin-8, interleukin-10, corticosteroid, $\beta_{2}$-adrenoceptor agonist, chronic obstructive pulmonary disease, chronic cor pulmonale the induced sputum IL-10 level, $\mathrm{FEV}_{1 \% \text { pred }}$ and the $\mathrm{PaO}_{2}$ were markedly increased in the three treatment groups compared with the values pre-therapy (all $\mathrm{P}<0.01$ ). The post-treatment parameters were significantly different among the three groups $(\mathrm{P}<0.01)$. The results indicate that IL-8 and IL-10 are involved in the airway inflammation of AECOPD complicated by CCP. Treatment with an ICS was demonstrated to be a successful method of reducing the local expression of IL-8 and increasing the local expression of IL-10; however, ICS combined with a long-acting $\beta_{2}$-adrenoceptor agonist (LABA) was more effective than the sole administration of ICS in patients with AECOPD complicated by CCP at high altitude.

\section{Introduction}

Chronic obstructive pulmonary disease (COPD) is a common respiratory disease characterized by an airflow limitation that is not fully reversible. The airflow limitation is usually progressive and is correlated with an abnormal inflammatory response of the lungs to noxious particles or gases. The disease may be prevented and treated; however, it develops progressively. In recent years, COPD morbidity and mortality have increased rapidly, and it has been revealed that the global incidence of COPD has reached up to $10 \%$ (1). There are 600 million patients worldwide, and COPD is fatal for 2.75 million people each year (2). While in 1990 COPD was the fourth leading cause of global mortality, it has been predicted that it is likely to rise to the third by 2020. It is one of the five most prevalent diseases $(3,4)$. Therefore, there is an urgent requirement for further studies into the pathogenesis and treatments of COPD. COPD is a chronic airway inflammation involving numerous cytokines and mediators of inflammation. The pathology of disease involves chronic and non-specific inflammation of the airway, lung parenchyma and pulmonary vessels and remodeling of the airway and vessel wall caused by repair. This leads to a progressive, persistent restriction to the air flow and a reduction in the lung function. A characteristic of acute inflammation is the high expression of inflammatory factors $(5,6)$. The inflammation in COPD is a complex reactive procedure, involving a multi-pathophysiological development, 
including tissue lesions, airway remodeling and high levels of mucous secretion. Interleukin-8 (IL-8), a selective neutrophil chemotactic factor, is a cytokine that promotes the inflammatory response, whereas IL-10, an anti-inflammatory cytokine, is important in the regulation of the inflammatory reaction $(7,8)$. It has been demonstrated that the level of IL-8 is increased and that of IL-10 is decreased significantly in the airways of patients with COPD in flatland areas (9-11). However, there has been limited investigation into the effects of the disease at altitude. Furthermore, the expression levels of IL-8 and IL-10 in the induced sputum of patients with acute exacerbated COPD (AECOPD) complicated by chronic cor pulmonale (CCP) have not yet been fully elucidated. Calverley et al (12) observed that an inhaled corticosteroid (ICS), combined with a long-acting $\beta_{2}$-adrenoceptor agonist (LABA) significantly suppressed inflammatory markers in patients with COPD in flatland areas, and notably improved clinical parameters. However, the correlation between the anti-inflammatory effects and the clinical improvement was not revealed. Furthermore, it was not determined whether IL- 8 and IL-10 exhibited any regulatory action.

In the present study, it was hypothesized that, at high altitude, IL- 8 and IL-10 in the induced sputum of patients with AECOPD complicated by CCP are likely to be expressed abnormally and involved in airway inflammation. It was further suggested that treatment with ICS/LABA combination inhalers was likely to be able to regulate this effect. Therefore the expression levels of IL-8 and IL-10 in the induced sputum of patients with AECOPD complicated by $\mathrm{CCP}$ at high altitude were investigated and the intervention effects of ICS/LABA combination inhalers were observed. The results of the study were used to elucidate the mechanism of the inflammatory reaction in the airways of patients with AECOPD complicated by CCP at altitude, to investigate the novel therapeutic approach and to provide a foundation for its use as an anti-inflammatory therapy.

\section{Subjects and methods}

Patients. A total of 186 patients with AECOPD complicated by CCP at altitude $(2,260 \sim 3,500 \mathrm{~m})$ who were hospitalized in the Department of Respiratory Medicine at The Fourth Hospital of PLA (Xining, China) from June 2010 to September 2012 were selected for this study. The diagnosis of COPD was consistent with the standard Guidelines for the Diagnosis and Treatment of COPD (2007 Revised Edition), established by the respiratory branch of the Chinese Medical Association (13), while CCP was diagnosed according to the corresponding Chinese diagnostic criteria (14). The patients were randomly divided into three groups, with 62 cases in each. Two of the three groups, groups A and B, were treatment groups. The first treatment group, group A, comprised 36 males and 26 females, aged from 46 to 77 years (mean age, 58.6 7.5 years), while in group B there were 33 males and 29 females, aged from 48 to 77 years (mean age, $58.1 \pm 7.4$ years). The routine treatment group (group C) comprised 35 males and 27 females, aged from 46 to 74 years (mean age, $57.9 \pm 7.2$ years), while the control group (group D) consisted of 26 male and 14 female healthy volunteers, aged from 50 to 72 years (mean age, $58.1 \pm 7.0$ years). The age and gender ratio in the three groups demonstrated no statistical significances (all $\mathrm{P}>0.05$ ). This study was conducted in accordance with the Declaration of Helsinki and with approval from the Ethics Committee of The Fourth Hospital of PLA. Written informed consent was obtained from all participants.

Medication program. Routine treatment, such as anti-infective agents, expectorants and aminophylline, was identical in the three groups. In addition to the routine treatment, the patients in group A were treated with ICS/LABA combination inhalers, containing salmeterol/fluticasone $(50 \mu \mathrm{g} / 250 \mu \mathrm{g}$, respectively), twice daily, while those in group B inhaled $1 \mathrm{mg}$ budesonide, twice daily. The patients in group $\mathrm{C}$ only received the routine treatment. The levels of IL- 8 and IL-10 in the induced sputum, in addition to the blood gas levels and the lung function parameters were determined respectively prior to treatment and at a stable point, two weeks following the treatment.

Arterial blood gas analysis. The partial pressure of oxygen in the arterial blood $\left(\mathrm{PaO}_{2}\right)$ and the partial pressure of carbon dioxide in the arterial blood $\left(\mathrm{PaCO}_{2}\right)$ for each patient were determined with $2 \mathrm{ml}$ femoral arterial blood by an OPTI ${ }^{\mathrm{TM}}$ CCA-TS blood gas analyzer (OPTI Medical Systems, Inc., Roswell, GA, USA) under room air respiratory conditions.

Lung function measurements. The percentage of forced expiratory volume in one second $\left(\mathrm{FEV}_{1}\right) /$ predicted $\mathrm{FEV}_{1}\left(\mathrm{FEV}_{1 \% \text { pred }}\right)$ and the $\mathrm{FEV}_{1}$ /forced vital capacity $(\mathrm{FVC})$ ratio $\left(\mathrm{FEV}_{1} / \mathrm{FVC}\right)$ were measured three times successively with a Spirolab-II spirometer (MIR-Medical International Research, Rome, Italy) and the maximum values were selected.

Induced sputum collection and handing. Prior to the experiment, each subject gargled with clear water and then inhaled $200 \mu \mathrm{g}$ salbutamol. After $15 \mathrm{~min}$, the patients inhaled ultrasonically nebulized $3 \%$ sodium chloride solution for $20 \mathrm{~min}$. The patients were told to gargle with hydrogen peroxide and blow out any nasal discharge prior to each deep expectoration. The expectorated sputum was collected in an aseptic polypropylene box. The sputum, without the salivary component, was placed into a centrifuge tube and then $0.1 \%$ dithiothreitol (DTT) solution was added, according to a 1:1 quality/volume ratio. This was then placed on an oscillator and mixed well by shaking softly at room temperature. The sputum and DTT mixture was then placed in a $37^{\circ}$ homeothermia swing bed for $15 \mathrm{~min}$ and centrifuged at $1,610 \mathrm{x} \mathrm{g}$ for $30 \mathrm{~min}$. The supernate was subsequently obtained and reserved at $-80^{\circ} \mathrm{C}$, while the sediment was used for cytological analysis. Qualifying specimens contained $<20 \%$ squamous cells and demonstrated a $50 \%$ cell survival rate.

Determination of IL-8 and IL-10 levels in the induced sputum. The concentrations of IL- 8 and IL-10 in the supernate of the induced sputum were determined by a double antibody sandwich enzyme-linked immunosorbent assay (ELISA). The reagents for the ELISA were purchased from Jingmei Biotechnology Co., Ltd. (Shenzhen, China), and were used in accordance with the manufacturer's instructions. The optical density value at $450 \mathrm{~nm}$ was measured using a Bio-Rad 3550 ELISA reader (Bio-Rad, Hercules, CA, USA), and the IL-8 and 
Table I. Comparison of IL-8 and IL-10 levels in the induced sputum, lung function parameters and arterial blood gas levels prior to treatment in the four groups.

\begin{tabular}{lcccccc}
\hline Group & IL-8 $(\mathrm{pg} / \mathrm{ml})$ & $\mathrm{IL}-10(\mathrm{pg} / \mathrm{ml})$ & $\mathrm{FEV}_{1 \% \mathrm{pred}}$ & $\mathrm{FEV}_{1} / \mathrm{FVC}(\%)$ & $\mathrm{PaO}_{2}\left(\mathrm{mmHg}^{2}\right)$ & $\mathrm{PaCO}{ }_{2}(\mathrm{mmHg})$ \\
\hline A & $408.56 \pm 43.57^{\mathrm{a}}$ & $34.57 \pm 7.33^{\mathrm{a}}$ & $31.85 \pm 5.72^{\mathrm{a}}$ & $37.12 \pm 6.86^{\mathrm{a}}$ & $32.84 \pm 5.52^{\mathrm{a}}$ & $58.96 \pm 6.21^{\mathrm{a}}$ \\
B & $402.15 \pm 42.85^{\mathrm{a}}$ & $34.80 \pm 7.08^{\mathrm{a}}$ & $32.36 \pm 6.28^{\mathrm{a}}$ & $37.35 \pm 6.34^{\mathrm{a}}$ & $32.62 \pm 6.09^{\mathrm{a}}$ & $59.13 \pm 6.53^{\mathrm{a}}$ \\
C & $395.67 \pm 42.60^{\mathrm{a}}$ & $35.63 \pm 7.14^{\mathrm{a}}$ & $32.34 \pm 6.25^{\mathrm{a}}$ & $36.97 \pm 6.13^{\mathrm{a}}$ & $33.16 \pm 5.45^{\mathrm{a}}$ & $59.47 \pm 6.09^{\mathrm{a}}$ \\
D & $132.20 \pm 12.63$ & $67.33 \pm 6.35$ & $71.15 \pm 6.53$ & $75.44 \pm 6.81$ & $65.36 \pm 5.33$ & $28.62 \pm 4.05$ \\
\hline
\end{tabular}

Data are presented as the mean \pm standard deviation. Group A, salmeterol/fluticasone treatment group; Group B, budesonide treatment group; Group C, routine treatment group; Group D, control group. ${ }^{a} \mathrm{P}<0.01$ compared with group D. IL, interleukin; $\mathrm{FEV}_{1}$, percentage of forced expiratory volume in one second; $\mathrm{FEV}_{1 \% \text { pred }}$, predicted $\mathrm{FEV}_{1} ; \mathrm{FVC}$, forced vital capacity; $\mathrm{PaO}_{2}$, partial pressure of oxygen in arterial blood; $\mathrm{PaCO}_{2}$, partial pressure of carbon dioxide in arterial blood.

Table II. Comparison of IL-8 and IL-10 levels in the induced sputum, lung function parameters and arterial blood gas levels following treatment in the three groups.

\begin{tabular}{lcccccc}
\hline Group & IL-8 $(\mathrm{pg} / \mathrm{ml})$ & $\mathrm{IL}-10(\mathrm{pg} / \mathrm{ml})$ & $\mathrm{FEV}_{1 \% \mathrm{pred}}$ & $\mathrm{FEV}_{1} / \mathrm{FVC}(\%)$ & $\mathrm{PaO}_{2}(\mathrm{mmHg})$ & $\mathrm{PaCO}$ \\
\hline A & $181.50 \pm 33.72^{\mathrm{ab}}$ & $54.22 \pm 6.54^{\mathrm{ab}}$ & $45.03 \pm 6.36^{\mathrm{ab}}$ & $47.88 \pm 6.30^{\mathrm{ab}}$ & $54.52 \pm 6.27^{\mathrm{ab}}$ & $41.43 \pm 4.28^{\mathrm{ab}}$ \\
B & $262.63 \pm 34.35^{\mathrm{ac}}$ & $47.19 \pm 7.25^{\mathrm{ac}}$ & $40.12 \pm 4.27^{\mathrm{ac}}$ & $45.24 \pm 5.30^{\mathrm{ac}}$ & $49.75 \pm 5.46^{\mathrm{ac}}$ & $45.77 \pm 5.23^{\mathrm{ac}}$ \\
C & $307.55 \pm 33.60^{\mathrm{a}}$ & $40.66 \pm 6.42^{\mathrm{a}}$ & $36.53 \pm 5.22^{\mathrm{a}}$ & $40.94 \pm 5.72^{\mathrm{a}}$ & $45.61 \pm 4.32^{\mathrm{a}}$ & $50.47 \pm 6.07^{\mathrm{a}}$ \\
\hline
\end{tabular}

Data are presented as the mean \pm standard deviation. Group A, salmeterol/fluticasone treatment group; Group B, budesonide treatment group; Group $\mathrm{C}$, routine treatment group. ${ }^{\mathrm{P}}<0.01$ compared with the value prior to treatment; ${ }^{\mathrm{b}} \mathrm{P}<0.01$ compared with groups $\mathrm{B}$ and $\mathrm{C}$; ${ }^{\mathrm{c}} \mathrm{P}<0.01$ compared with group C. IL, interleukin; $\mathrm{FEV}_{1}$, percentage of forced expiratory volume in one second; $\mathrm{FEV}_{1 \% \text { pred }}$, predicted $\mathrm{FEV}$; $\mathrm{FVC}_{\text {, forced }}$ vital capacity; $\mathrm{PaO}_{2}$, partial pressure of oxygen in arterial blood; $\mathrm{PaCO}_{2}$, partial pressure of carbon dioxide in arterial blood.

IL-10 concentrations were calculated following the drawing of a standard curve.

Statistics analysis. The experimental data, expressed as the mean \pm standard deviation, were analyzed using SPSS 17.0 statistical software (SPSS, Inc., Chicago, IL, USA). Multi-interclass mean differential significance analysis was performed using analysis of variance, while self pre- and post-therapy values were compared using a paired t-test and correlation analysis was performed using a Pearson rectilinear analysis. The criteria of inspection were $\mathrm{a}=0.05$ and $\mathrm{P}<0.05$, where comparisons with these values were considered to indicate a statistically significant difference.

\section{Results}

Induced sputum IL-8 and IL-10 levels, lung function parameters and arterial blood gas levels prior to treatment. The induced sputum IL-8 level and the $\mathrm{PaCO}_{2}$ were significantly higher, while the induced sputum IL-10 level, the $\mathrm{FEV}_{1 \% \text { pred }}$, the $\mathrm{FEV}_{1} / \mathrm{FVC}$ and the $\mathrm{PaO}_{2}$ were significantly lower in the three COPD groups compared with those in the control group (all $\mathrm{P}<0.01$ ). However, there were no significant differences among the three COPD groups (all P>0.05; Table I).

Comparison of induced sputum IL-8 and IL-10 levels, lung function parameters and arterial blood gas levels following treatment. Compared with the pre-therapy values, the induced sputum IL-8 level and the $\mathrm{PaCO}_{2}$ were reduced, while the induced sputum IL-10 level, the $\mathrm{FEV}_{1 \% \text { pred }}$, the $\mathrm{FEV}_{1} / \mathrm{FVC}$ and the $\mathrm{PaO}_{2}$ were increased significantly (all $\mathrm{P}<0.01$ ) in the three COPD groups. Furthermore, significant differences were apparent among the three groups (all $\mathrm{P}<0.01$; Table II).

Correlation analysis of $I L-8$ and $I L-10$ levels in the induced sputum with lung function parameters and arterial blood gas levels. The induced sputum IL- 8 level was negatively correlated with $\mathrm{FEV}_{1 \% \text { pred }}, \mathrm{FEV}_{1} / \mathrm{FVC}$ and $\mathrm{PaO}_{2}($ all $\mathrm{P}<0.001)$ and positively correlated with $\mathrm{PaCO}_{2}$. The IL-10 level was significantly positively correlated with $\mathrm{FEV}_{1 \% \text { pred }}, \mathrm{FEV}_{1} / \mathrm{FVC}$ and $\mathrm{PaO}_{2}$, and negatively correlated with $\mathrm{PaCO}_{2}($ all $\mathrm{P}<0.001)$ in all patients prior to treatment (Table III).

\section{Discussion}

IL-8 is a type of chemotactic factor that is important in the activation of neutrophilic granulocytes. It is synthesized in and secreted from alveolar macrophages, airway epithelial cells, neutrophils and lymphocytes. IL-8 is able to stimulate neutrophils to change shape, promoting degranulation and leading to the release of superoxide dismutase and lysosomal enzymes, which enhance the inflammatory reaction, resulting in airway and lung parenchyma inflammation and damage, accordingly. IL-8 is the predominant cytokine in the sputum of patients with COPD that induces neutrophil chemotaxis (15-17). IL-10 is synthesized in $\mathrm{CD}_{4}{ }^{+}$or $\mathrm{CD}_{8}{ }^{+} \mathrm{T}$-lymphocytes, macrophages, 
Table III. Correlation analysis of induced sputum IL-8 and IL-10 levels, lung function parameters and arterial blood gas levels prior to treatment in 186 patients

\begin{tabular}{|c|c|c|c|c|c|c|c|c|}
\hline \multirow[b]{2}{*}{ Parameters } & \multicolumn{2}{|c|}{$\mathrm{FEV}_{1 \% \text { pred }}$} & \multicolumn{2}{|c|}{$\mathrm{FEV}_{1} / \mathrm{FVC}$} & \multicolumn{2}{|c|}{$\mathrm{PaO}_{2}$} & \multicolumn{2}{|c|}{$\mathrm{PaCO}_{2}$} \\
\hline & r value & P-value & r value & P-value & r value & P-value & r value & P-value \\
\hline IL-8 & -0.726 & $<0.001$ & -0.667 & $<0.001$ & -0.688 & $<0.001$ & 0.658 & $<0.001$ \\
\hline IL-10 & 0.673 & $<0.001$ & 0.648 & $<0.001$ & 0.667 & $<0.001$ & -0.599 & $<0.001$ \\
\hline
\end{tabular}

$\mathrm{IL}$, interleukin; $\mathrm{FEV}_{1}$, percentage of forced expiratory volume in one second; $\mathrm{FEV}_{1 \% \text { pred }}$, predicted $\mathrm{FEV}_{1} ; \mathrm{FVC}$, forced vital capacity; $\mathrm{PaO}{ }_{2}$, partial pressure of oxygen in arterial blood; $\mathrm{PaCO}_{2}$, partial pressure of carbon dioxide in arterial blood.

monocytes, eosinophils and the airway epithelium. Macrophages and monocytes are the primary cells that generate endogenous IL-10. The function of IL-10 is to inhibit and terminate the inflammatory reaction, and to inhibit the synthesis and release of the proinflammatory cytokines. Therefore, IL-10 possesses anti-inflammatory effects $(7,18)$.

The primary purpose of our study was to observe the expression of IL- 8 and IL-10 in the induced sputum of patients with AECOPD complicated by $\mathrm{CCP}$ at high altitude. The results revealed that the induced sputum IL-8 level was significantly higher, whereas the induced sputum IL-10 level was significantly lower in the three COPD groups compared with the healthy control group, prior to treatment. It is possible that the increased levels of proinflammatory cytokines and decreased levels of anti-inflammatory cytokines in the airways of the patients with AECOPD complicated by CCP at high altitude may be the mechanism behind the enhanced inflammatory reaction in the airway. The results support our hypothesis and are in concurrence with the results from a previous study on COPD, conducted in flatland areas (8). $\mathrm{CD}_{8}^{+}$lymphocyte, macrophage and neutrophil levels have been demonstrated to increase in bronchial biopsy tissue, while IL-8, IL-6, tumor necrosis factor- $\alpha$ (TNF- $\alpha$ ) and their soluble receptor levels have been demonstrated to increase significantly in the circulation and airducts of patients with COPD in flatland areas, indicating that persistent chronic inflammation is present in COPD (19). Furthermore, IL-8, leukotriene B4 (LTB4) and myeloperoxidase (MPO) levels in the sputum have been revealed to increase markedly in patients with AECOPD in flatland areas (20), as well as increasing in bronchial biopsy tissue and in the blood; however, the IL-10 concentration was observed to decrease significantly $(10,11)$. The results of the present study revealed that the level of IL-8 in the induced sputum was significantly negatively correlated with $\mathrm{FEV}_{1 \% \text { pred }}, \mathrm{FEV}_{1} / \mathrm{FVC}$ and $\mathrm{PaO}_{2}$, and was significantly positively correlated with $\mathrm{PaCO}_{2}$. In addition, the level of IL-10 was observed to be significantly positively correlated with $\mathrm{FEV}_{1 \% \text { pred }}, \mathrm{FEV}_{1} / \mathrm{FVC}$ and $\mathrm{PaO}_{2}$, and significantly negatively correlated with $\mathrm{PaCO}_{2}$ in patients with AECOPD, complicated by CCP, at altitude. The results indicate that the IL-8 level in the sputum increased and the IL-10 level in the sputum decreased along with the extent of the airflow limitation in patients with AECOPD complicated by CCP at altitude. This was in concurrence with the results of a study conducted in flatland areas, which demonstrated that the more severe the airway obstruction in the patient with COPD in flatland areas, the higher the IL- 8 concentration in the sputum (20
(MIR-Medical International Research, Rome, Italy)). The IL-8 concentration in the sputum has been observed to be negatively correlated with $\mathrm{FEV}_{1}$, while the IL-10 concentration in the sputum has been revealed to be positively correlated with $\mathrm{FEV}_{1 \% \text { pred }}$ and $\mathrm{FEV}_{1} / \mathrm{FVC}(8,11,21,22)$. All the previously mentioned results demonstrate that the increased secretion of the proinflammatory cytokine, IL-8, and the decreased secretion of the anti-inflammatory cytokine, IL-10, are involved in the pathogenesis of COPD, and change along with the severity of the airflow limitation. Thus, the inhibition of IL- 8 and the promotion of IL-10 synthesis possess important clinical significance with regard to the control of airway inflammation in COPD and the improvement of the condition and lung function of the patients.

The results of our study indicate that the increase in IL-8 levels and reduction in IL-10 levels in the induced sputum of patients with AECOPD complicated by $\mathrm{CCP}$ at altitude, were more severe than those in flatland areas $(10,11,19)$. This may be due to a number of reasons, such as the fact that altitude presents a special hypoxic environment. Under such conditions, patients with AECOPD complicated by CCP suffer from the combined effects of environmental hypoxia and an anoxic disease, and, therefore, the hypoxemia of patients at altitude is more severe than those in flatland areas. In addition, the patients in the current study suffered from COPD complicated by $\mathrm{CCP}$; thus, their condition was more severe than that of patients solely with COPD in flatland areas. Furthermore, large differences in temperature and air quality may lead to repeated airway infection and acute exacerbation in patients with COPD. All these factors may have resulted in a more severe airway inflammation in patients with AECOPD complicated by CCP than in those in flatland areas.

In addition to assessing the expression of IL-8 and IL-10 in the induced sputum, the purpose of our study was to observe the intervention effects of an ICS combined with a LABA on the levels of IL- 8 and IL-10 in the induced sputum of patients with AECOPD complicated by CCP at altitude. The results revealed that the induced sputum IL- 8 level and the $\mathrm{PaCO}_{2}$ decreased significantly, while the induced sputum IL-10 level, $\mathrm{FEV}_{1 \% \text { pred }}, \mathrm{FEV}_{1} / \mathrm{FVC}$ and the $\mathrm{PaO}_{2}$ increased significantly in the three groups with COPD following treatment, compared with the levels measured pre-therapy. Furthermore, there were significant differences in the parameters among the three groups. It was demonstrated that, along with reductions in the IL-8 level and increases in the IL-10 level, the airway inflammation was reduced and the extent of the airflow limitation 
was improved following ICS treatment. In addition, ICS was able to effectively suppress the synthesis or secretion of the proinflammatory cytokine, IL-8, and promote the synthesis or secretion of the anti-inflammatory cytokine, IL-10.

The ICS/LABA combination inhalers produced the most efficacious results, followed by the sole use of ICS, while the conventional therapy was the least effective. This was consistent with our hypothesis and similar to the results from a previous study concerning COPD in flatland areas (23). The salmeterol/fluticasone propionate combination inhaler has been reported to significantly lessen airway hyper-inflammation in patients with COPD in flatland areas $(24,25)$; the effect of the combination inhaler on inflammatory cells in COPD exceeded the effects of the inhalation or oral intake of corticosteroids alone. The regular inhalation of corticosteroids by patients with COPD in flatland areas is able to postpone the rapidity of the decline in lung function, reduce the episodes of acute exacerbation, ease disease severity, mitigate gasping and improve the quality of life, while the inhalation of an ICS combined with a LABA results in a more marked improvement in every parameter (26). The ability of salmeterol/fluticasone to reduce the acute exacerbation or severity of COPD has been demonstrated to be particularly notable (27). It has been revealed that the therapeutic effect of an ICS combined with a LABA surpasses the effect of an ICS used by itself. A possible mechanism for this is through the glucocorticosteroid mediating the upregulation of $\beta_{2}$-adrenoceptor gene transcription, thus increasing the density and quantity of the $\beta_{2}$-adrenoceptors on the cell surface and enhancing the sensitivity of the bronchial smooth muscle to $\beta_{2}$-adrenoceptor agonists. In addition, the LABA may accelerate the translocation of glucocorticoid receptors to the leucocytic nucleus, promoting glucocorticoid-sensitive gene transcription and enhancing its anti-inflammatory activity. Glucocorticoids act at the airway inflammation, while LABAs act at the smooth muscle of the airway. Combining a glucocorticoid with a LABA produces a synergistic effect that may effectively depress airway inflammation and improve corticosteroid sensitivity (28). This represents a key intervention for preventing and treating AECOPD, in addition to preventing its development by inhibiting the non-specific airway inflammation or interrupting the cytokine-mediated inflammatory pathway. A study by Patel et al (29) revealed that the airway epithelium of patients with COPD displayed a significant cytokine response following inflammatory stimulation, and that there was a marked reduction in IL- 8 secretion following the administration of an ICS. Armstrong et al (30) reported that the activation of $\mathrm{p} 38$ mitogen-activated protein kinase (MAPK) decreased pulmonary alveolar macrophage sensitivity to glucocorticoids, while a p38 MAPK inhibitor combined with a glucocorticoid was able to strengthen the anti-inflammatory action by suppressing cytokine secretion.

The current study suggests that ICS/LABA combination inhalers may effectively control airway inflammation in patients with AECOPD complicated by CCP, abate airflow limitations and improve the condition of the patients. ICS/LABA combination inhalers are a safe and valid approach for treating COPD complicated by CCP and their effects surpass those of simple ICS therapy.

Further studies are required to investigate the reason why levels of IL- 8 increase and the levels of IL-10 decrease more markedly in the sputum of patients with AECOPD compli- cated by CCP at altitude than in those in flatland areas. In addition, we have planned a comparative study comparing simple COPD at altitude with that in flatland areas.

\section{References}

1. Agustí A and Vestbo J: Current controversies and future perspectives in chronic obstructive pulmonary disease. Am J Respir Crit Care Med 184: 507-513, 2011.

2. Dalal AA, Liu F and Riedel AA: Cost trends among commercially insured and Medicare Advantage-insured patients with chronic obstructive pulmonary disease: 2006 through 2009. Int J Chron Obstruct Pulmon Dis 6: 533-542, 2011.

3. Lopez AD, Shibuya K, Rao C, et al: Chronic obstructive pulmonary disease: current burden and future projections. Eur Respir J 27: 397-412, 2006.

4. Rabe KF, Hurd S, Anzueto A, et al; Global Initiative for Chronic Obstructive Lung Disease: Global strategy for the diagnosis, management, and prevention of chronic obstructive pulmonary disease: GOLD executive summary. Am J Respir Crit Care Med 176: 532-555, 2007.

5. Parr DG, White AJ, Bayley DL, Guest PJ and Stockley RA: Inflammation in sputum relates to progression of disease in subjects with COPD: a prospective descriptive study. Respir Res 7: 136, 2006

6. GOLD Executive Committee: Global strategy for the diagnosis, management, and prevention of chronic obstructive pulmonary disease (Revised 2011) [EB/OL]. http://www.goldcopd.com. Accessed February 22, 2012.

7. Asadullah K, Sterry W and Volk HD: Interleukin-10 therapy review of a new approach. Pharmacol Rev 55: 241-269, 2003.

8. Hacievliyagil SS, Gunen H, Mutlu LC, Karabulut AB and Temel I: Association between cytokines in induced sputum and severity of chronic obstructive pulmonary disease. Respir Med 100: 846-854, 2006.

9. Ko FW, Leung TF, Wong GW, et al: Measurement of tumor necrosis factor-alpha, leukotriene B4, and interleukin 8 in the exhaled breath condensate in patients with acute exacerbations of chronic obstructive pulmonary disease. Int J Chron Obstruct Pulmon Dis 4: 79-86, 2009.

10. O'Donnell R, Breen D, Wilson S and Djukanovic R: Inflammatory cells in the airways in COPD. Thorax 61: 448-454, 2006.

11. Kochetkova EA, Volkova MV, Surovenko TN and Gel'tser BI: Cytokine status in patients with chronic obstructive pulmonary diseases and its relationship with bone tissue functional state. Ter Arkh 76: 23-27, 2004 (In Russian).

12. Calverley PM, Anderson JA, Celli B, et al; TORCH investigators: Salmeterol and fluticasone propionate and survival in chronic obstructive pulmonary disease. N Engl J Med 356: 775-789, 2007.

13. COPD Working Group of Chinese Medical Association respiratory disorder branch. Guidelines for the Diagnosis and Treatment of COPD (2007 Revised Edition). Chin J Tuberc Respir Dis 30: 8-17, 2007 (In Chinese).

14. Chen HZ (ed): Practical Internal Medicine. 11th edition. People's Health Publishing House, Beijing, pp1449-1452, 2001.

15. Oudin S and Pugin J: Role of MAP kinase activation in interleukin-8 production by human BEAS-2B bronchial epithelial cells submitted to cyclic stretch. Am J Respir Cell Mol Biol 27: 107-114, 2002.

16. Powrie DJ, Wilkinson TM, Donaldson GC, et al: Effect of tiotropium on sputum and serum inflammatory markers and exacerbations in COPD. Eur Respir J 30: 472-478, 2007.

17. Chung KF: Inflammatory mediators in chronic obstructive pulmonary disease. Curr Drug Targets Inflamm Allergy 4: 619-625, 2005.

18. Gong MN, Thompson BT, Williams PL, et al: Interleukin-10 polymorphism in position -1082 and acute respiratory distress syndrome. Eur Respir J 27: 674-681, 2006.

19. Wilson SJ, Wallin A, Della-Cioppa G, Sandström T and Holgate ST: Effect of budesonide and formoterol on NF-kappaB, adhesion molecules, and cytokines in asthma. Am J Respir Crit Care Med 164: 1047-1052, 2001.

20. Kersul AL, Iglesias A, Ríos Á, et al: Molecular mechanisms of inflammation during exacerbations of chronic obstructive pulmonary disease. Arch Bronconeumol 47: 176-183, 2011.

21. Takanashi S, Hasegawa Y, Kanehira Y, et al: Interleukin-10 level in sputum is reduced in bronchial asthma, COPD and in smokers. Eur Respir J 14: 309-314, 1999. 
22. Burgess JL, Nanson CJ, Hysong TA, Gerkin R, Witten ML and Lantz RC: Rapid decline in sputum IL-10 concentration following occupational smoke exposure. Inhal Toxicol 14: 133-140, 2002

23. Liu SX, Zhang GJ, Wang HQ, Chen SS and Chu HY: Effect of inhaled glucocorticoids/long-acting $\beta 2$-agonist on chronic obstructive pulmonary disease. International Journal of Respiration 29: 129-131, 2009 (In Chinese).

24. Barnes NC, Qiu YS, Pavord ID, et al; SCO30005 Study Group: Antiinflammatory effects of salmeterol/formoterol propionate in chronic obstructive lung disease. Am J Respir Crit Care Med 173: 736-743, 2006

25. Bourbeau J, Christodoulopoulos P, Maltais F, Yamauchi Y, Olivenstein R and Hamid Q: Effect of salmeterol/fluticasone propionate on airway inflammation in COPD: a randomised controlled trial. Thorax 62: 938-943, 2007.

26. Celli BR, Thomas NE, Anderson JA, et al: Effect of pharmacotherapy on rate of lung function in chronic obstructive pulmonary disease: results from the TORCH study. Am J Respir Crit Care Med 178: 332-338, 2008.
27. Fenton $\mathrm{C}$ and Keating GM: Inhaled salmeterol/fluticasone propionate: a review of its use in chronic obstructive pulmonary disease. Drugs 64: 1975-1996, 2004

28. Marwick VM and Chung KF: Glucocorticoid insensitivity as a future target of therapy for chronic obstructive pulmonary disease. Int J Chron Obstruct Pulmon Dis 5: 297-309, 2010.

29. Patel IS, Roberts NJ, Lloyd-Owen SJ, Sapsford RJ and Wedzicha JA: Airway epithelial inflammatory responses and clinical parameters in COPD. Eur Respir J 22: 94-99, 2003.

30. Armstrong J, Harbron C, Lea S, et al: Synergistic effects of p38 mitogen-activated protein kinase inhibition with a corticosteroid in alveolar macrophages from patients with chronic obstructive pulmonary disease. J Pharmacol Exp Ther 338: 732-740, 2011. 